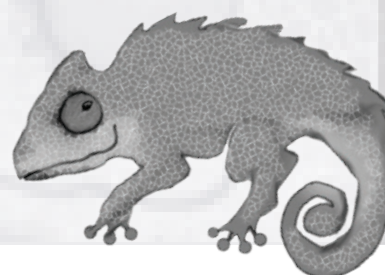

\section{ECOS DE UN SEMINARIO INTERNACIONAL}

El movimiento pacifista colombiano está en pleno desarrollo. Esa es la conclusión que puede extraerse de la exitosa celebración del III Seminario Internacional de Noviolencia: "Está sucediendo. Otros mundos son posibles" realizado entre el 10 y el 13 de Noviembre del 2009 en las instalaciones de la Corporación Universitaria Minuto de Dios en Bogotá.

En un mismo espacio confluyeron los indígenas delCauca-representados en elCRIC y en la Guardia Indígena-; los representantes de "el Coro de las Abejas" de la resistencia pacífica de Chiapas en México; intelectuales chilenos, españoles y mexicanos; delegados de numerosas ciudades colombianas que hacen parte del Movimiento Ciudadano por la noviolencia; profesores e investigadores de varias universidades del país; organizaciones sociales y comunitarias de derechos humanos, y más de 350 pacifistas venidos de poblaciones y ciudades de Colombia. Este entusiasmo por debatir las perspectivas e implicaciones de la Noviolencia es de mucha significación y rebasó las expectativas de los más optimistas.

La construcción de una mirada profunda, vívida e interdisciplinar, que enriquece la discusión académica y la conducción práctica de la pluralidad de ejercicios de paz que habitan en las redes sociales de nuestro país, se hizo más visible gracias a la novedosa metodología centrada en la puesta en escena de 11 grandes experiencias de acción noviolenta de todo el país, comentadas a
Editorial

la luz de 18 ponencias (entre ellas las de 6 ponentes internacionales) y analizadas en los debates adelantados por todos los asistentes a través del funcionamiento de 27 mesas de trabajo y 3 plenarias. El punto de partida fue el conocimiento de prácticas vivas de resistencia y acción noviolenta y una reflexión desde los más diversos ámbitos del pensamiento, con mucho énfasis en la cultura; así, los asistentes hicieron un esperanzador balance y una promisoria apertura de la segunda década del siglo que corre. Es de mucha trascendencia que esta praxis sea objeto de la atención de los centros de pensamiento y que sean cada vez más numerosas las líneas y proyectos de investigación que procuran, desde grupos altamente calificados, abordar estos nuevos problemas.

El trabajo de organización de tan grande evento corrió por cuenta de la Facultad de Ciencias Humanas y Sociales, en cabeza de de la Escuela de Paz y Desarrollo y del Centro de Estudios e Investigaciones Humanas y Sociales (CEIHS), en colaboración con el Centro de Educación para el Desarrollo (CED) de UNIMINUTO. La alianza con grandes centros universitarios como la Universidad de La Salle (Facultad de Filosofía), la Universidad Nacional Abierta y a Distancia, La Universidad Javeriana (Facultad de Filosofía), así como con el Instituto Nacional de Medicina Legal y Ciencias Forenses, La Alcaldía Mayor deBogotá, FICONPAZ, elCINEP y cerca de 30 importantes organizaciones sociales y no gubernamentales, lo mismo que por reconocidos organismos de cooperación internacional (Diakonía Suecia, Centro mundial de solución de conflictos, 
Kaired) hicieron posible este encuentro para la acción y la reflexión. El Seminario Internacional se vinculó además con otros tres grandes momentos del trabajo de los y las pacifistas: La Semana por la Paz, en el mes de Septiembre, La Cumbre Mundial por la Paz en el mes de Octubre y la Marcha Mundial por la Paz y la Noviolencia que culminó en el mes de Diciembre.

Sin lugar a dudas, muchos hechos de paz están poblando nuestra geografía, anunciando otros mundos. Las prácticas de la resistencia noviolenta permiten que resuenen palabras como las del poeta vietnamita Thich Naht Hanh:

"La paz verdadera siempre es posible, aunque requiere fuerzay práctica, sobretodo en tiempos de gran dificultad. Para algunos, la paz y la noviolencia son sinónimos de pasividad y debilidad. En realidad, practicar la paz y la noviolencia está muy lejos de la pasividad. Practicar la paz, hacer que la paz viva en nosotros, es cultivar activamente la comprensión, el amor y la compasión, incluso cuando nos enfrentamos a la incomprensión y a conflicto. Practicar la paz, en especial en tiempos de guerra, requiere coraje."

La octava edición de nuestra revista Polisemia incluye ocho artículos y reseñas, organizados en nuestras habituales secciones.

En la sección "Pensamiento Social" se acoge el artículo "Educación para el desarrollo: un estado del arte" del investigador del CED, Rigoberto Solano. En este texto se identifican elementos conceptuales y diversas formas de abordar un tema que se ha convertido en uno de los puntos neurálgicos del debate pedagógico y de la orientación práctica de la responsabilidad social: la Educación para el Desarrollo. La construcción del estado del arte del problema, incluye una mirada a los aportes de diferentes organizaciones e instituciones en el mundo, con el propósito de enriquecer los saberes en esta materia y proponer a futuro un modelo de formación basado en tales reflexiones. Producto de una investigación en curso, de la cual se ha agotado la primera etapa, el artículo de Solano constituye un aporte crítico al abordaje de esa compleja relación entre educación, desarrollo, solidaridad y ciudadanía, evaluando los ensayos que se han tenido en América Latina desde conceptos "desarrollistas" y oteando el futuro desde miradas alternativas en busca de un desarrollo humano sustentable.

El texto "¿Haciendo el nudo en la horca? Nuevas tecnologías y participación" de dos investigadores de la Corporación "Red Camaleón. Sistema de Información Joven", nos permite retomar el tema de los estudios de juventud que hemos abordado en otras ocasiones en Polisemia. Julián Quintero y Denis Rojas nos presentan en esta ocasión opiniones documentadas y un análisis sociológico sobre temas emergentes para la juventud, especialmente radicada en el ámbito urbano, entre ellos los referidos al uso, por parte de los jóvenes, de los nuevos medios de comunicación e información y su impacto en la agenda pública. La pregunta por si estas nuevas TICs se constituyen en escenarios relevantes para la participación política y el encuentro de los mundos juveniles diversos, cobra toda actualidad y pertinencia. El interrogante: ¿Se avanza hacia una ciudadanía virtual, o hacia un autismo social? hace referencia a las personas jóvenes que van adquiriendo cada vez mayores competencias para socializar en las redes de Internet y parecen ir perdiendo condiciones para la movilización y la expresión pública generadoras de intensas relaciones interpersonales.

En otro artículo, Myriam Sandoval presenta sus "Reflexiones sobre la familia: una aproximación paralaconstruccióndepolíticas familiares". Sandoval aborda el problema de la familia como parte del entramado social y desde una perspectiva ética y política, planteándose el cuestionamiento de ¿hasta qué punto las políticas públicas son acordes con el momento histórico de la realidad donde subyacen?. Por tanto, se intenta 
una aproximación a la reflexión sobre la construcción de políticas familiares para concretarlas, en la realidad de cada familia, y se enfatiza en la necesidad de partir desde aspectos propios a su ciclo vital, en el que se involucren vivencias, vínculos y afectos.

El artículo presenta una mirada panorámica de las discusiones sobre la composición de la familia actual. Esta descripción, actualiza la caracterización de nuevas modalidades de unión familiar como la familia monoparental o la aparición, en el terreno del derecho civil, de los derechos de la comunidad homosexual y se pregunta al respecto, por el problema de la inclusión en las políticas públicas. El texto hace parte de una investigación en curso que adelanta el Programa de Trabajo Social de UNIMINUTO, y puede ser leído también desde perspectivas como las del análisis crítico que, desde hace varias décadas, se ha planteado comprender la crisis de esta institución teniendo en cuenta su dimensión de dispositivo de socialización de naturaleza disciplinar (M. Foucault). Sea bienvenido el debate al respecto.

La sección de "Reflexiones Filosóficas" se abre en este número con el artículo "La concepción del hombre de Friedrich Hayek", de Jorge Vergara, investigador de la Universidad de Chile que hace parte del Grupo de investigación del CEIHS y que nos acompaña habitualmente en POLISEMIA. Vergara expone en este artículo los principales antecedentes intelectuales de la concepción del hombre expuestas por el teórico de la "escuela austriaca" cuyas ideas fueron soporte del pensamiento neoliberal contemporáneo.

El artículo analiza dos planos del planteamiento de Hayek en esta materia: De una parte, ofrece una concepción de lo que es el hombre: un ser individualista, cuya evolución histórica conduce desde "la sociedad tribal" a la "sociedad extendida", y es un ser creador de normas y tradiciones. Se trataría de un tipo de individualismo liberal, opuesto al individualismo racionalista de los enciclopedistas franceses, de Stuart Mill, J. Dewey o Keynes que, según él, está inspirado en el colectivismo. De otra, cómo es el hombre, se caracterizan sus dimensiones principales: su ética es heterónoma e inmanente a la reproducción de la sociedad; su razón es limitada; la libertad es su valor central, aunque se limita a la libertad económica, cuyo ámbito de ejercicio por excelencia es el mercado $y$, finalmente, sostiene que los hombres son naturalmente desiguales. El artículo de Vergara es un aporte para dilucidar las bases de la antropología de Hayek, que, como reconoce el articulista, se ha convertido en un clásico de la teoría económica y social contemporánea.

En esta sección se presenta también el artículo "Entre el hombre libre y el Dios bueno. Acerca de la fundamentación moral de la certeza en la filosofía de Descartes" de la filósofa Diana Marcela Pinto. Aquí se hace una aproximación a elementos de la teoría del conocimiento planteada por Descartes, cuyo argumento racional ubica a Dios, como un ser moralmente perfecto, en el papel de avalador del conocimiento, deslindándolo de la posibilidad otorgada al hombre de ir desde sí mismo al conocimiento y de tomar una decisión sobre lo que su entendimiento le presenta. Se manifiestan así dos aspectos fundamentales: la libertad infinita de Dios, y la total libertad epistémico que éste le brinda al hombre. De esta manera, en la teoría cartesiana el conocimiento involucra también un perfil moral, ya que implica elección, y esto le permite al filósofo francés librar a Dios de la responsabilidad de la aparición del error en el conocimiento humano.

Finaliza la sección "Reflexiones Filosóficas" el muy interesante artículo de nuestro colaborador en París, el sociólogo mexicano Luís Martínez Andrade. "Un acercamiento al proceso gnoseológico desde la perspectiva de Edgar Morin y Paul Feyerabend". El texto analiza el discurso científico, y en particular el "método científico"como un campo de luchas y enfrentamientos, así como en instrumento 
de legitimación de determinados intereses políticos. Por eso se hace necesario observar la dinámica social en la que está inscrito el discurso, las formas como se apropian de él los sujetos y las luchas por el derecho a la inclusión que se libran en el ámbito del conocimiento y de la comunicación.

Martínez Andrade plantea que la distribución igualitaria del derecho a participar en la comunicación y el conocimiento es lograda a través de luchas, combates y resistencia; y para ello hace falta crear un espacio político que permita dialogar con distintas perspectivas que van a contracorriente de lo que plantea la pretensión de la existencia de un pensamiento único. En esta dirección el articulista reivindica las propuestas metodológicas y los planteamientos teóricos de Morin y Feyerabend en la medida en que pueden ser de gran utilidad en los procesos de análisis e intervención en el terreno no sólo epistemológico sino socio-político.

Laseccióncaminosdepazynoviolenciaacoge el artículo "Cultura estudiantil y diversidad sexual. Discriminación y reconocimiento de los y las jóvenes LGBT en la secundaria" del investigador Erik Cantor. El texto se plantea el problema de la discriminación que subsiste frente a orientaciones sexuales e identidades de género diversas, centrándose en el análisis de la cultura estudiantil que predomina en los colegios de secundaria con respecto a jóvenes homosexuales, lesbianas y transgeneristas en Bogotá, a partir de los resultados del estudio sobre homofobia y convivencia en la escuela, realizado entre los años 2006 y 2007.

Cantor profundiza su crítica -sostenida en otras importantes publicaciones- al predominio y reproducción del sistema sexo/ género/heterosexismo como un paradigma cultural naturalizado, que circula en la escuela a través del currículo oculto, y se materializa en el conjunto de creencias, emociones y comportamientos que determinan la exclusión y la discriminación. El estudio hace un rastreo de las expresiones de homofobia y lesbofobia a nivel emocional, cognitivo y de comportamientos predominantes entre los(as) estudiantes de secundaria, así como a las consecuencias sobre los(as) estudiantes que son víctimas de estas agresiones.

Además, describe el impacto de la homofobia y la lesbofobia entre los(as) estudiantes que son víctimas de discriminación por orientación sexual e identidad de género y enuncia algunos lineamentos generales para abordar esta situación desde los procesos de educación sexual que tendrían que se concebidos desde una perspectiva integral y de convivencia pacífica basada en los derechos y en el respeto por la dignidad del otro ser humano.

En la sección de "Avances y Reseñas" se da cabida al texto "El nuevo capitalismo y la 'ciudad dual': entre lo local y lo cosmopolita ante el impacto de la tecnología" de Oscar Iván Useche, colaborador de esta edición de POLISEMIA. Se trata de una incursión en una de las más recientes publicaciones del sociólogo y urbanista Manuel Castells "La ciudad informacional. Tecnología de la información, reestructuración económica y el proceso urbano-regional". Useche resume el problema planteado por Castells en el sentido de que las condiciones de clase social, derivadas de los modelos económicos impuestos o adoptados por la sociedad contemporánea, reestructuran los espacios urbanos en función del nivel de acceso a la información.

Dejamos entonces a disposición de los lectores esta octava edición de POLISEMIA, esperando alimentar la pluralidad de visiones y opiniones. Tal vez así contribuyamos a suscitar el espíritu crítico e investigativo, que es otra forma de "caminar la palabra", que es la metáfora con la que los pueblos indígenas nombran ese ejercicio intenso del resistir desde la afirmación de la vida.

\section{OSCAR USECHE}

DIRECTOR DE POLISEMIA 